Article

\title{
Experimental Investigation and Optimization of the Semisolid Multicavity Squeeze Casting Process for Wrought Aluminum Alloy Scroll
}

\author{
Yi Guo ${ }^{1}$, Yongfei Wang ${ }^{2,3,4, *}$ and Shengdun Zhao ${ }^{2}[$ \\ 1 School of Energy and Power Engineering, Xi'an Jiaotong University, Xi'an 710049, China; \\ yiguo666@mail.xjtu.edu.cn \\ 2 School of Mechanical Engineering, Xi'an Jiaotong University, Xi'an 710049, China; sdzhao@mail.xjtu.edu.cn \\ 3 State Key Laboratory of Fluid Power and Mechatronic Systems, Zhejiang University, \\ Hangzhou 310027, China \\ 4 State Key Laboratory of Materials Processing and Die and Mould Technology, Huazhong University of \\ Science and Technology, Wuhan 430074, China \\ * Correspondence: wangyongfei324@mail.xjtu.edu.cn; Tel.: +86-134-881-268-40
}

Received: 28 October 2020; Accepted: 20 November 2020; Published: 21 November 2020

\begin{abstract}
Scroll compressors are popularly applied in air-conditioning systems. The conventional fabrication process causes gas and shrinkage porosity in the scroll. In this paper, the electromagnetic stirring (EMS)-based semisolid multicavity squeeze casting (SMSC) process is proposed for effectively manufacturing wrought aluminum alloy scrolls. Insulation temperature, squeeze pressure, and the treatment of the micromorphology and mechanical properties of the scroll were investigated experimentally. It was found that reducing the insulation temperature can decrease the grain size, increase the shape factor, and improve mechanical properties. The minimum grain size was found as $111 \pm 3 \mu \mathrm{m}$ at the insulation temperature of $595^{\circ} \mathrm{C}$. The maximum tensile strength, yield strength, and hardness were observed as $386 \pm 8 \mathrm{MPa}, 228 \pm 5 \mathrm{MPa}$, and $117 \pm 5 \mathrm{HV}$, respectively, at the squeeze pressure of $100 \mathrm{MPa}$. The tensile strength and hardness of the scroll could be improved, and the elongation was reduced by the $\mathrm{T} 6$ heat treatment. The optimal process parameters are recommended at an insulation temperature in the range of $595-600^{\circ} \mathrm{C}$ and a squeeze pressure of $100 \mathrm{MPa}$. Under the optimal process parameters, scroll casting was completely filled, and there was no obvious shrinkage defect observed inside. Its microstructure is composed of fine and spherical grains.
\end{abstract}

Keywords: wrought aluminum alloy; scroll compressor; semisolid forming process; microstructure; mechanical property

\section{Introduction}

Scroll compressors are popularly applied in air-conditioning systems because of numerous benefits, including high volumetric efficiency, low noise, low leakage, and low vibrations [1,2]. Due to excellent compression performance, scroll compressors are also recommended for use in fuel cell systems [3] or the energy storage field [4]. The main and key parts of scroll compressors are two interfitting scrolls, which form a positive displacement and compress the working fluid by rotating [5]. The scroll-forming method is crucial for the manufacturing and production of scroll compressors because of the complex shape with involute curves [6]. Hot forging and machining processes are generally used to fabricate scrolls for a typical refrigeration scroll compressor. However, some drawbacks are observed during these manufacturing processes, which include low efficiency, high production cost, and low material usage coefficient [7-9]. High-pressure die casting has also been applied for the fabrication of scrolls, 
but the turbulent flow in this process causes gas and shrinkage porosity [10] because of the high filling rate [11].

Gas and shrinkage porosity can be effectively eliminated by squeeze casting technology, which has been recommended to manufacture the complex component from aluminum alloys and aluminum metal-matrix composites [12-14]. The semisolid squeeze casting (SSSC) process, which combines the excellent filling performance of a semisolid metal with the characteristics of squeeze casting technology $[15,16]$, is one of the most widely used semisolid metal-forming (SSMF) techniques. It integrates the easy fluidity of the liquid casting process and the high mechanical properties of solid-state plastic forming and is considered one of the most promising metal processing technologies of the 21st century [17-19]. In the SSSC process, a semisolid slurry is first injected into a mold cavity. The rheological filling, crystallization solidification, rheological feeding, and a small amount of plastic deformation are then performed under pressure. The high-strength product with a dense interior, accurate size, and few macro- and microdefects can finally be obtained after the SSSC process [20].

In recent decades, research on the SSSC process has drawn the attention of scholars. Lü et al. [21] investigated the effects of the SSSC process on the microstructure and mechanical properties of the long period stacking ordered (LPSO)-structure-reinforced $\mathrm{Mg}_{97} \mathrm{Zn}_{1} \mathrm{Y}_{2}$ alloy. It was found that the structure of LPSO and $\alpha-\mathrm{Mg}$ grains in the studied alloy can be dramatically improved by the SSSC process. Wang et al. [22] proposed SSSC to fabricate ZL104-alloy-connecting rods. The influences of remelting temperature, mold temperature, and squeeze pressure on the mechanical properties of the connecting rod were investigated. It was concluded that tensile strength and elongation were increased by $22 \%$ and $17 \%$, respectively, through the SSSC process. Zhai et al. [23] studied the structure evolution and mechanical properties of the ZL109 alloy prepared by the SSSC process. It was revealed that the sphericity of the $\alpha$ phase and the refining of the silicon phase could be obtained due to the friction between solid and liquid. The elongation of the ZL109 alloy rose to $1.42 \%$ when heat treatment was performed after the SSSC process. Masoumi et al. [24] studied the influence of applied pressure on the microstructure and tensile properties of the Mg-Al-Ca alloy. They pointed out the tensile properties of casting increased with increased applied pressures, which can be attributed to the casting densification and presence of a high amount of solute in the matrix.

The preparation of a semisolid billet is an indispensable step for the SSSC process. Electromagnetic stirring (EMS) is a contactless technique commonly applied to produce forced convection and adjust fluid flow during the solidification of the metal melt, which has become one of the main methods for the production of semisolid slurry or billets [25,26]. EMS works similar to the induction motor, which contains a stator and a rotor [27]. When the three-phase alternating current is supplied to the windings of the stator, the induced magnetic field is produced in this field. The induction current is obtained when the rotor cuts the induced magnetic field. When the rotor is replaced by the melt metal bulk, EMS initiation is achieved. Compared to traditional stirring, several benefits to flow control and grain refinements, such as nonoxidation [28], nonpollution [29], continuous production [30], and easy operation [31], can be obtained by the EMS technique.

Due to the drawbacks of the conventional process method and the advantages of the SSSC and EMS techniques, the EMS-based semisolid multicavity squeeze casting (SMSC) process is proposed in this paper for manufacturing aluminum alloy scrolls. This work aims to effectively improve the production efficiency, microstructure, and mechanical properties of the scroll. Firstly, the near-final forming of the scroll can be realized via the processed process, significantly improving the material utilization rate. Secondly, the concept of one mold for four castings can be verified, visibly improving the production efficiency. Thirdly, the semisolid billet with fine and spherical grains can be prepared by the EMS process, improving the mechanical properties of the scroll. The effects of insulation temperature, squeeze pressure, and the heat treatment of the micromorphology and the mechanical properties of the scroll were investigated experimentally, based on which optimal process parameters were obtained for the manufacturing of scrolls by the EMS-based SMSC process. 


\section{Materials and Methods}

The commercial wrought aluminum alloy 2A50 (Aluminum Corporation of China Limited, Beijing, China) was used as the experimental material in this work. Its chemical components are summarized in Table 1, which shows that the main alloy element is copper. The solidus and liquidus temperatures of the studied material are $521^{\circ} \mathrm{C}$ and $615^{\circ} \mathrm{C}$, respectively. This means that the semisolid temperature range is as wide as up to $94^{\circ} \mathrm{C}$, which is suitable for semisolid casting. Information on the structure and dimensions of the studied scroll for a typical scroll compressor applied in the automotive air conditioning is shown in Figure 1.

Table 1. Chemical composition of 2A50 aluminum alloy (wt.\%).

\begin{tabular}{ccccccccc}
\hline $\mathbf{C u}$ & $\mathbf{S i}$ & $\mathbf{M g}$ & $\mathbf{M n}$ & $\mathrm{Zn}$ & $\mathrm{Ti}$ & $\mathrm{Ni}$ & $\mathbf{F e}$ & $\mathrm{Al}$ \\
\hline 2.43 & 0.82 & 0.68 & 0.53 & 0.12 & 0.06 & 0.05 & 0.01 & Surplus \\
\hline
\end{tabular}
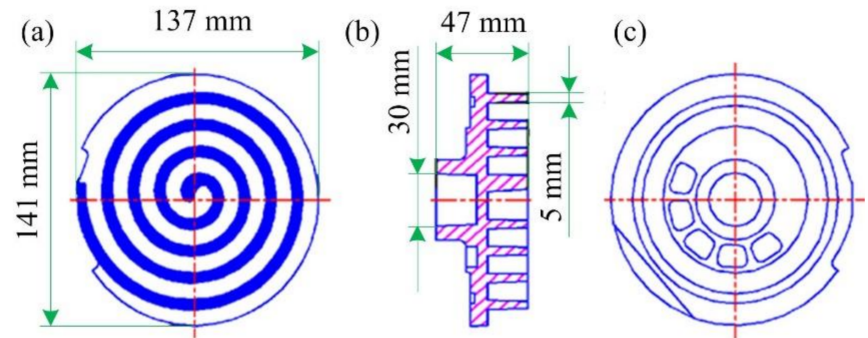

Figure 1. Structure and dimensions of the scroll for scroll compressors applied in automotive air conditioning: (a) front view, (b) sectional view, and (c) back view.

The EMS-based SMSC process of one die with four aluminum alloy scrolls proposed in this paper mainly includes four stages, as shown in Figure 2. (A) Stage I: The 2A50 aluminum alloy semisolid billet is prepared by electromagnetic stirring. The pouring temperature of the molten metal is $645{ }^{\circ} \mathrm{C}$, and the preheating temperature of the stirring chamber is $350{ }^{\circ} \mathrm{C}$. The winding current and the electrical frequency of the EMS are set as $30 \mathrm{~A}$ and $30 \mathrm{~Hz}$, respectively. (B) Stage II: The second remelting of the semisolid billet is performed at a set insulation temperature for $15 \mathrm{~min}$. (C) Stage III: The semisolid multicavity squeeze forming of the scroll is performed under the designed pressure by using a multicavity squeeze casting hydraulic press (Xi'an Jiaotong University, Xi'an, China), as shown in Figure 3a, and a multicavity squeeze forming mold, as shown in Figure 3b, where the preheating temperature of the mold is $350^{\circ} \mathrm{C}$. (D) Stage IV: T6 heat treatment is performed on the formed scrolls, which mainly includes a solution treatment and aging treatment. This stage is performed at a solution temperature of $495^{\circ} \mathrm{C}$ for $5 \mathrm{~h}$ and an aging temperature of $180{ }^{\circ} \mathrm{C}$ for $8 \mathrm{~h}$.

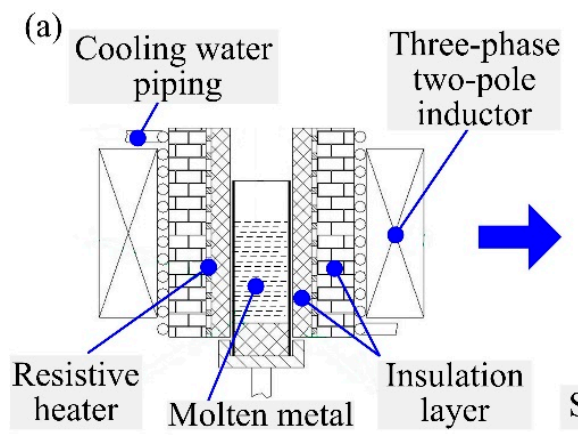

(b)

(c)

(d)
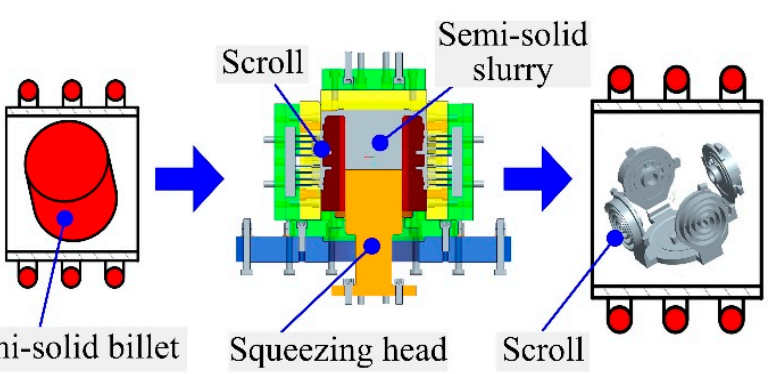

Figure 2. Electromagnetic stirring (EMS)-based semisolid multicavity (SMSC) process of one mold for four aluminum alloy scrolls: (a) Stage-EMS preparation, (b) Stage II—remelting, (c) Stage III—forming process, and (d) Stage IV-T6 heat treatment. 
(a)

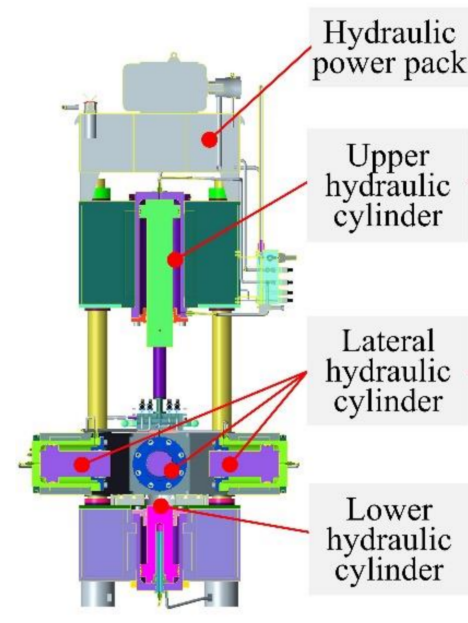

(b)

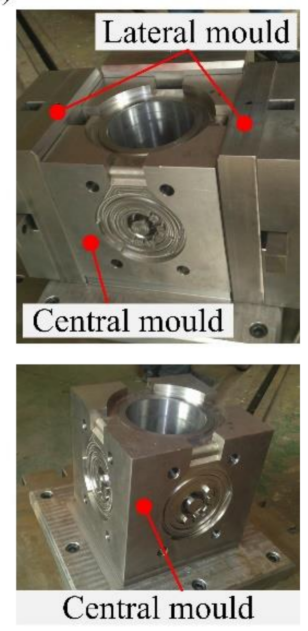

Figure 3. (a) The multicavity squeeze casting hydraulic press and (b) the multidirection squeeze forming mold for manufacturing scrolls.

In this paper, 8 multicavity squeeze experiments were performed to investigate the effects of the operating parameters on the microstructure evolution of the scrolls. As shown in Table 2, the operating parameters studied in this paper contain the insulation temperature in Stage II and the squeeze pressure in Stage III. In order to compare and analyze the advantages of the semisolid forming process compared with the near-liquidus and liquid-forming process, a liquid temperature of $645{ }^{\circ} \mathrm{C}$, a near-liquidus temperature of $615^{\circ} \mathrm{C}$, and semisolid temperatures of 600 and $595{ }^{\circ} \mathrm{C}$ were designed in Experiments 1-4, respectively, to study the effect of insulation temperature on the microstructures. The squeeze pressure varied from 25 to $125 \mathrm{MPa}$ to reveal the effects of squeeze pressure on the microstructures. In Experiments 1-4, the squeeze pressure was set at $100 \mathrm{Mpa}$ with variation in the insulation temperature, whereas in Experiments 4-8, the insulation temperature was set at $595^{\circ} \mathrm{C}$ with a change in the squeeze pressure. It is worthy to note that the insulation temperature in Experiments 5-8 was designed based on the results from Experiments 1-4 to only investigate the effects of different squeeze pressures without the variation in the insulation temperature. All 8 experiments were performed with the T6 heat treatment.

Table 2. Experimental process parameters.

\begin{tabular}{cccc}
\hline $\begin{array}{c}\text { Experimental } \\
\text { Number }\end{array}$ & $\begin{array}{c}\text { Insulation Temperature } \\
\left({ }^{\circ} \mathbf{C}\right)\end{array}$ & $\begin{array}{c}\text { Squeeze Pressure } \\
(\mathbf{M p a})\end{array}$ & $\begin{array}{c}\text { Heat } \\
\text { Treatment }\end{array}$ \\
\hline 1 & 645 & 100 & $\mathrm{~T} 6$ \\
2 & 615 & 100 & $\mathrm{~T} 6$ \\
3 & 600 & 100 & $\mathrm{~T} 6$ \\
4 & 595 & 100 & $\mathrm{~T} 6$ \\
5 & 595 & 25 & $\mathrm{~T} 6$ \\
6 & 595 & 50 & $\mathrm{~T} 6$ \\
7 & 595 & 75 & $\mathrm{~T} 6$ \\
8 & 595 & 125 & $\mathrm{~T} 6$ \\
\hline
\end{tabular}

A schematic diagram of the whole semisolid multicavity squeeze process for fabricating four scrolls under one mold is illustrated in Figure 4. Under the action of the squeeze head, the semisolid slurry flows from the vertical and horizontal runner to the ingate runner and fills the mold cavity. The gas and redundant semisolid slurry flow out from the overflow trough. The scrolls can then be fabricated after the solidification of semisolid slurry. Through this designed mold, symmetry in the filling flow of the semisolid materials for the four scrolls can be achieved in the squeeze process. 


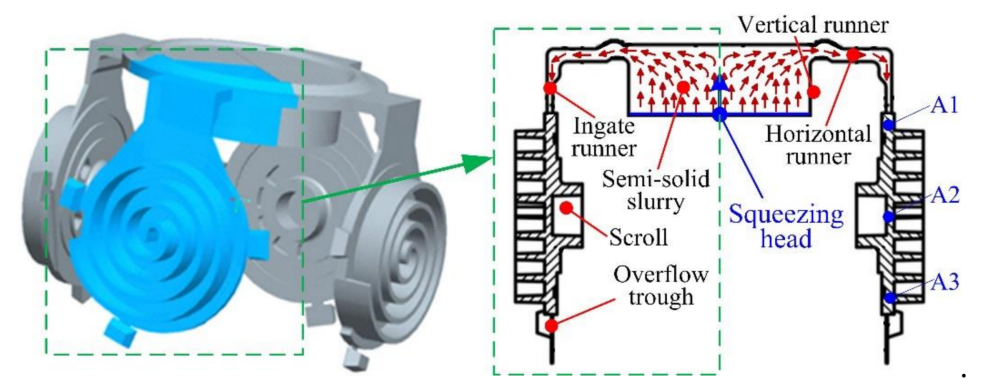

Figure 4. Schematic diagram of the whole SMSC process for fabricating four scrolls with one mold.

Considering the symmetry of the proposed semisolid multicavity squeeze method, one of the four scrolls was sampled for the investigation in this work. Three samples from the scrolls processed at different operating parameters were collected to study the microstructures. These samples were located at the inner gate (Position A1), the central region of the scroll (Position A2), and the bottom region of the scroll (Position A3), as shown in Figure 4. The microstructure of the samples was observed by an optical microscope (NIKON ECLIPSE LV 150N, Nikon, Tokyo, Japan) from 10 different fields of view for each sample, based on which the average grain diameter and shape factor of the metallographic structure were firstly measured using the Image-Pro Plus 6.0 software (Media Cybernetics, Rockville, MD, USA) and quantitatively analyzed by Equations (1) and (2) [32], respectively. Samples from the central region of the scroll (Position A2) were used for testing the mechanical properties by using a universal materials tester (INSTRON 5982, Instron, Norfolk, MA, USA) and a hardness tester (HV-1000, Shanghai Shangcai Testermachine Co.,Ltd, Shanghai, China). For obtaining the tensile strength, yield strength, and elongation, samples were stretched to break at the speed of $2 \mathrm{~mm} / \mathrm{min}$. In order to test the hardness, samples were processed under a test load of $200 \mathrm{~g}$ with a pressure holding time of $15 \mathrm{~s}$. The error of all the experimental data in this work was represented by the standard deviation.

$$
\begin{aligned}
& D=\frac{\sum_{N=1}^{N} \sqrt{4 A / \pi}}{N}, \\
& F=\frac{\sum_{N=1}^{N} 4 \pi A / P^{2}}{N},
\end{aligned}
$$

where $D$ is the average equivalent diameter of the crystal grains, $A$ is the area of the crystal grain, $P$ is the circumference of the crystal grain, $N$ is the number of the crystal grains, and $F$ is the average shape factor of the crystal grains.

\section{Results and Discussion}

\subsection{Effects of Insulation Temperature on the Microstructures and Mechanical Properties}

The microstructures of the sample collected from Position A2 formed at liquid temperature $\left(645^{\circ} \mathrm{C}\right)$, near-liquidus temperature $\left(615^{\circ} \mathrm{C}\right)$, and semisolid temperatures $\left(600\right.$ and $\left.595^{\circ} \mathrm{C}\right)$ are shown in Figure 5. It was found that the grain size significantly reduced, and the morphology improved when the insulation temperature dropped from the liquid state to a semisolid value. It is shown in Figure 5a that the morphology of crystal grains was extremely poor when Stage II was performed at a liquid temperature, where most of the coarse dendrites were more than $200 \mu \mathrm{m}$ in length. Compared to the liquid-forming process, it was found that the grain morphology evolved to the rose shape, and the grain size was obviously reduced when Stage II was performed at the near-liquidus temperature, which is presented in Figure 5b. When Stage II was performed at the semisolid temperatures, the microstructure was observed with a round morphology and small sizes. 

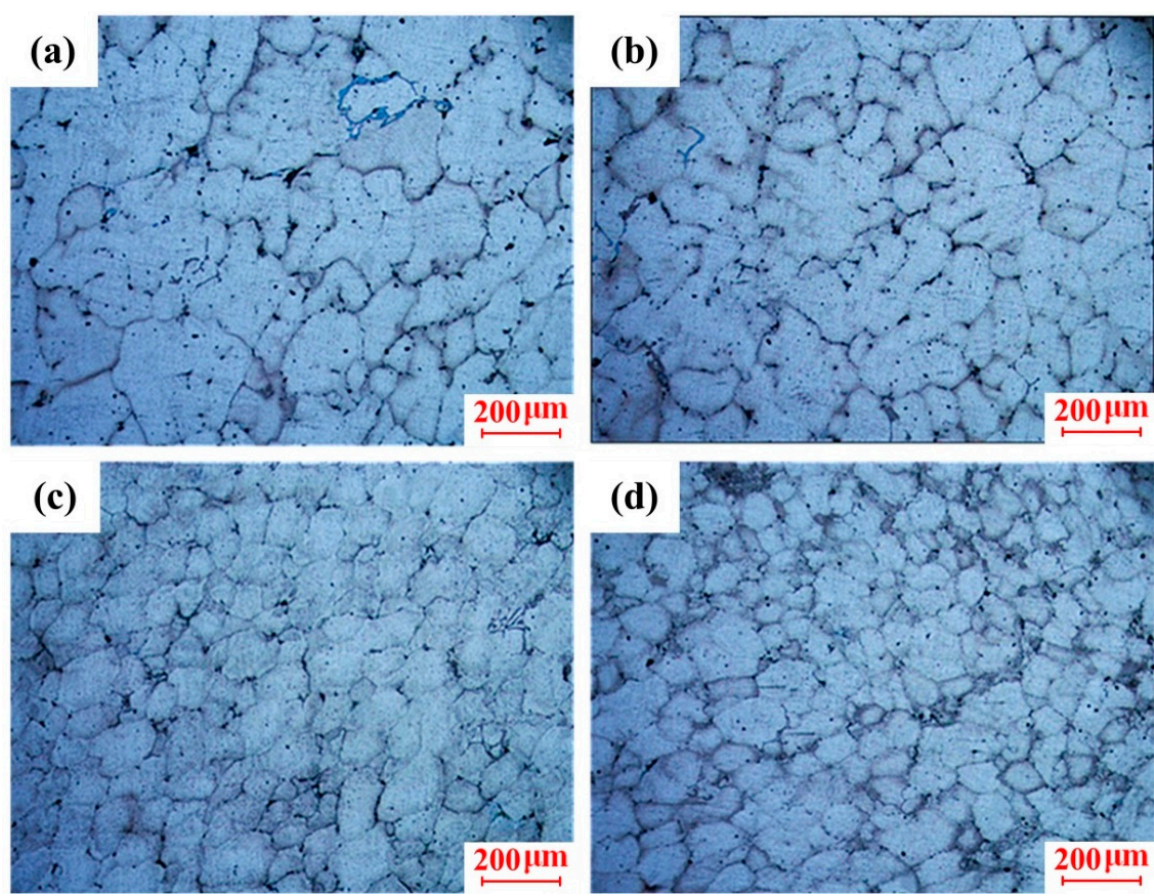

Figure 5. Microstructure of scroll under different holding temperature: (a) $645^{\circ} \mathrm{C},(\mathrm{b}) 615^{\circ} \mathrm{C},(\mathrm{c}) 600^{\circ} \mathrm{C}$, and (d) $595^{\circ} \mathrm{C}$.

The effects of the insulation temperature in Stage II on the average grain size and shape factor are summarized in Figure 6. A general increase in the average size and a general reduction in the shape factor were found when the insulation temperature varied from 595 to $645^{\circ} \mathrm{C}$. A rapid increase in the average grain size from $119 \pm 4$ to $238 \pm 24 \mu \mathrm{m}$ was observed, whereas the shape factor significantly decreased from $0.62 \pm 0.06$ to $0.54 \pm 0.09$ when the insulation temperature increased from 600 to $615^{\circ} \mathrm{C}$. A slight increase in the average grain size (from $238 \pm 24$ to $288 \pm 32 \mu \mathrm{m}$ ) and a slight drop in the shape factor (from $0.54 \pm 0.09$ to $0.52 \pm 0.09$ ) were observed with the increasing of insulation temperature from 615 to $645^{\circ} \mathrm{C}$. This was because when the degree of the superheat was reduced near the liquidus temperature, the nucleation rate and grain proliferation increased while the thick dendritic arms were fragmented during the filling and flow process. The morphology of crystal grains therefore gradually changed from liquid-formed coarse dendrites to rose-like crystal grains. In terms of the semisolid forming, in other words, the insulation temperature varied in the semisolid temperature range, reducing the insulation temperature of the blank can reduce the coarsening time of the crystal grains during the filling process and effectively limit the excessive growth of the crystal grains to ensure the crystal grains have a smaller size and a relatively high roundness.

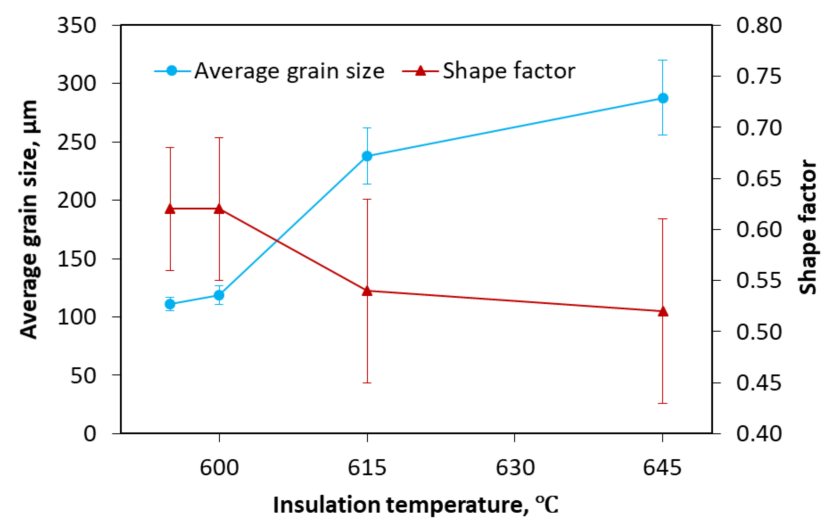

Figure 6. Effects of insulation temperature on the average grain size and shape factor. 
The mechanical properties investigated in this study are tensile strength, yield strength, elongation, and hardness. The mechanical properties of the scroll after the T6 heat treatment at different insulation temperatures in Stage II are presented in Figure 7. It was found that the tensile strength, yield strength, elongation, and hardness increased and almost stabilized when the insulation temperature dropped from the liquid state to the semisolid temperature range. The tensile strength increased from $272 \pm 25$ to $385 \pm 9 \mathrm{MPa}$ when the insulation temperature decreased from 645 to $600^{\circ} \mathrm{C}$, which further rose to $386 \pm 8 \mathrm{MPa}$ at the insulation temperature of $595^{\circ} \mathrm{C}$. The elongation of the scroll was measured as $5.4 \pm 1.2 \%$ at the insulation temperature of $645^{\circ} \mathrm{C}$, which significantly increased to $7.5 \pm 0.5 \%$ and $7.6 \pm 0.5 \%$ at the insulation temperatures of 600 and $595{ }^{\circ} \mathrm{C}$, respectively. An increase in the yield strength was observed from $163 \pm 13 \mathrm{MPa}$ at the insulation temperatures of $645^{\circ} \mathrm{C}$ to $228 \pm 5 \mathrm{MPa}$ and $595^{\circ} \mathrm{C}$. The hardness of the scroll was observed as $85 \pm 9$ and $95 \pm 8 \mathrm{HV}$ at the insulation temperatures of 645 and $615^{\circ} \mathrm{C}$, respectively, which dramatically increased up to $117 \pm 5 \mathrm{HV}$ at the insulation temperature of $595^{\circ} \mathrm{C}$. This improvement in the mechanical property of the scroll was because the primary crystal grains with uniform size and round shape can be obtained at the semisolid temperature. These improved crystal grains can effectively reduce the microscopic stress concentration generated by the coarse dendrites formed at the liquid-state temperature and slow down the formation and expansion of voids. Moreover, when the insulation temperature was relatively high at the liquidus or near-liquidus temperatures, the turbulent jetting of the slurry would take place during the filling process due to the low viscosity, which would cause the internal defects inside the scroll and the consequently low mechanical properties. The improvement in the yield strength with the decrease in the insulation temperature was because of the reduced grain size, which can be expressed by the classical Hall-Petch relationship, as shown in Equation (3) [33,34]

$$
\sigma_{y}=\sigma_{0}+k_{y} d^{-1 / 2}
$$

where $\sigma_{0}$ is the intrinsic lattice strength, $d$ is the average grain size and $k_{y}$ is the Hall-Petch coefficient.
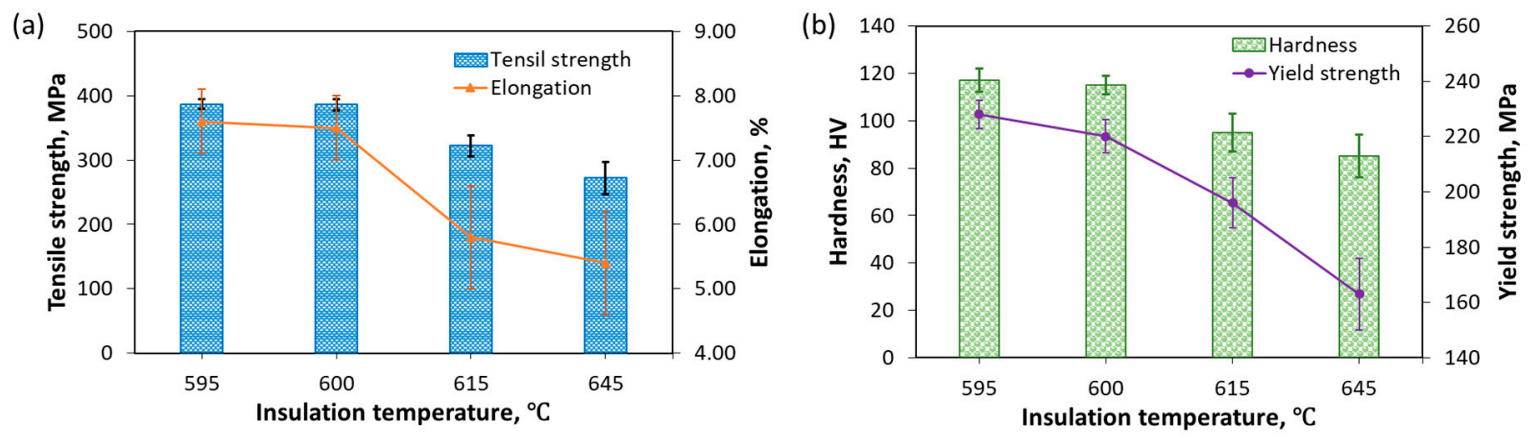

Figure 7. Effects of insulation temperature on the mechanical property of scrolls: (a) tensile strength and elongation; (b) yield strength and hardness.

\subsection{Effects of Squeeze Pressure on the Microstructures and Mechanical Properties}

According to the analysis in Section 3.2, it was found that the microstructure and mechanical properties of the scroll were between 595 and $600{ }^{\circ} \mathrm{C}$. Therefore, the insulation temperature was designed as $595{ }^{\circ} \mathrm{C}$ to investigate the effects of the squeeze pressure without the variation in the insulation temperature for the purpose of energy saving. The microstructures of the scroll at the central region prepared by different squeeze pressures from 25 to $125 \mathrm{MPa}$ in Stage III are shown in Figure 8. As shown in Figure 8a, under the squeeze pressure of $25 \mathrm{MPa}$, the crystal grains are round and uniform. When the squeeze pressure increased to $50 \mathrm{MPa}$, the grain size with the relatively round grain morphology slightly reduced, as presented in Figure 8b. However, the grain distribution became dense, with some grains coming into contact with each other, resulting in blurred grain boundaries and the slightly deteriorated grain morphology when the squeeze pressure increased up to $75 \mathrm{Mpa}$, 
which is presented in Figure 8c. When the squeeze pressure further increased to $125 \mathrm{MPa}$, a lot of crystal grains were adhered to and merged with each other. The newly merged crystal grains have different morphologies. During the high-pressure filling process, grains were coarsened to form a large number of grain clusters with fuzzy grain boundaries, which caused the large size grains and morphology deterioration.
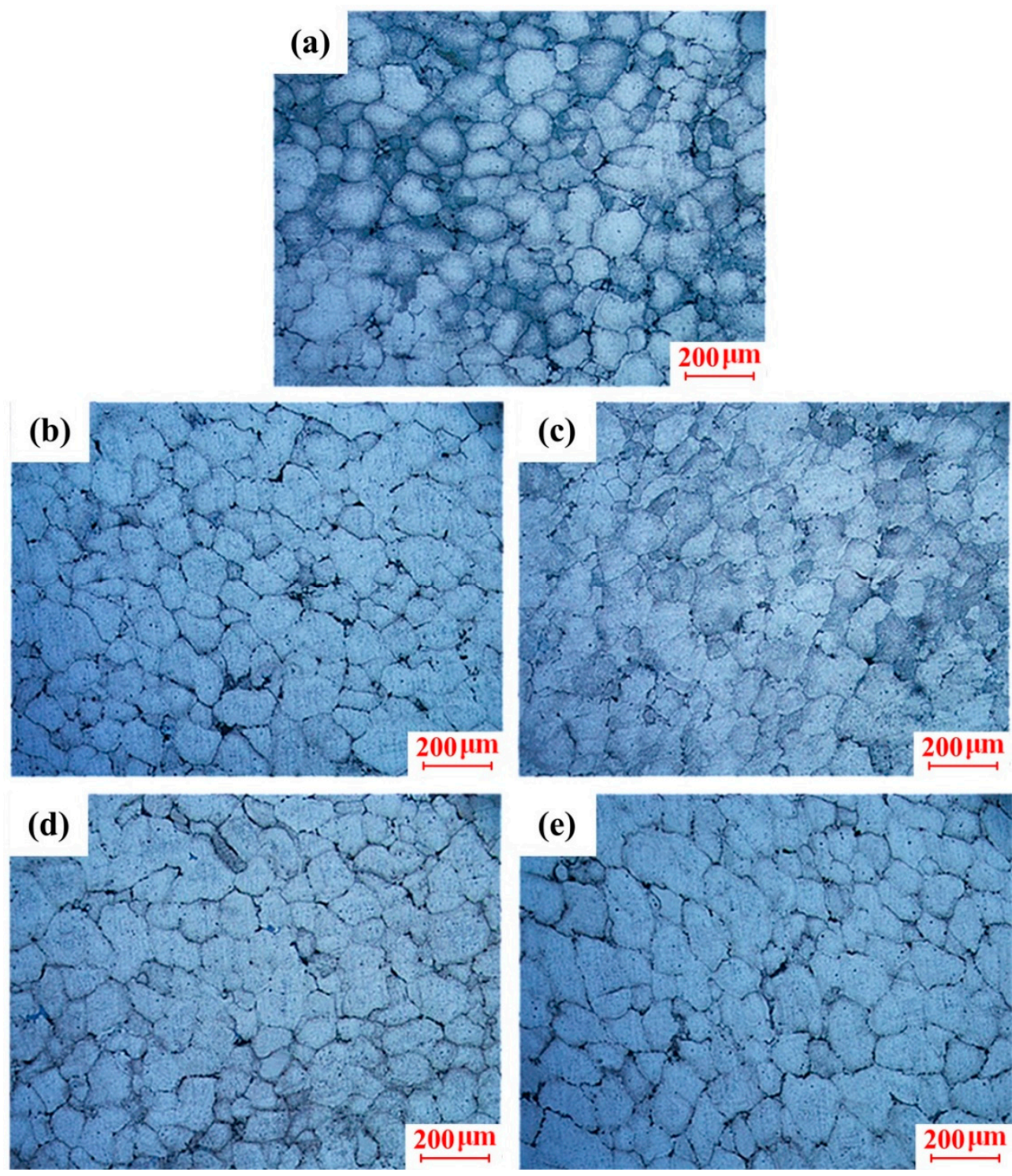

Figure 8. Microstructure of the scroll under different squeeze pressures: (a) $25 \mathrm{MPa}$, (b) $50 \mathrm{MPa}$, (c) $75 \mathrm{MPa}$, (d) $100 \mathrm{MPa}$, and (e) $125 \mathrm{MPa}$.

The effects of the squeeze pressure on the average grain size and shape factor of the scroll are presented in Figure 9. It was found that the average grain size slightly decreased from $116 \pm 4$ to $112 \pm 3 \mu \mathrm{m}$ when the squeeze pressure increased from 25 to $50 \mathrm{MPa}$. After that, with the increase in the squeeze pressure in Stage III, the average grain size slightly grew up to $113 \pm 3 \mu \mathrm{m}$ at the squeeze pressure of $75 \mathrm{MPa}$ and rapidly increased to $130 \pm 4 \mu \mathrm{m}$ at the squeeze pressure of $125 \mathrm{MPa}$. The shape factor showed a significant decrease from $0.74 \pm 0.05$ to $0.60 \pm 0.07$ when the squeeze pressure varied from 25 to $75 \mathrm{MPa}$. It had a slight increase when the squeeze pressure was $100 \mathrm{MPa}$ but further reduced to $0.54 \pm 0.08$ with the squeeze pressure of $125 \mathrm{MPa}$. 


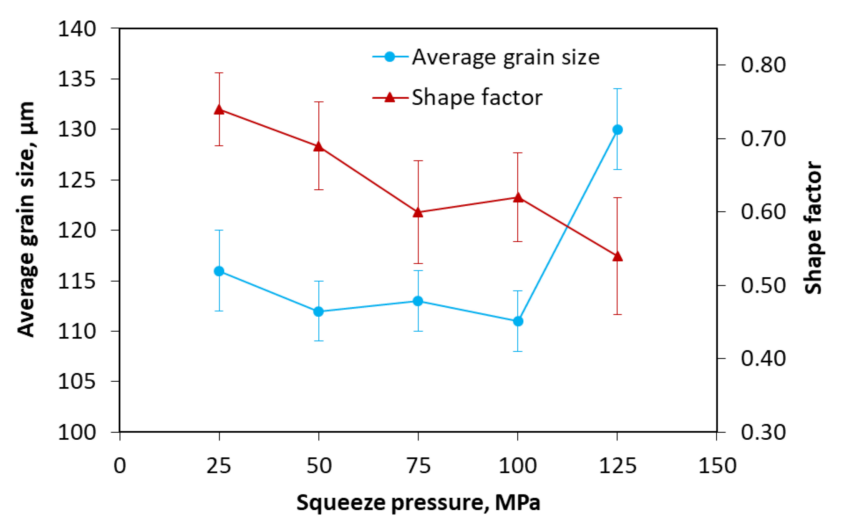

Figure 9. Effects of squeeze pressure on the average grain size and shape factor.

In the process of semisolid squeeze casting, the liquidus temperature of the metal slightly increases, and the cooling for the slurry is improved with the increase in the squeeze pressure, which consequently influences the microstructure of the scroll. The influence of squeeze pressure on the liquidus line of the alloy can be illustrated by the Clausius-Clapeyron equation, as shown in Equation (4) [35].

$$
\frac{\Delta T_{f}}{\Delta P}=\frac{T_{f}\left(V_{l}-V_{s}\right)}{\Delta H_{f}}
$$

where $T_{f}$ is the equilibrium solidification temperature, $\mathrm{K} ; V_{l}$ is the volumetric specific heat capacity of liquid metal, $\mathrm{J} /(\mathrm{kg} \cdot \mathrm{K}) ; V_{s}$ is the volumetric specific heat capacity of solid metal, $\mathrm{J} /(\mathrm{kg} \cdot \mathrm{K}) ; \Delta H_{f}$ is the latent heat of metal fusion, $\mathrm{J} / \mathrm{g} ; P$ is the squeeze pressure, MPa.

The results of Figure 9 can be explained by the Clausius-Clapeyron equation. According to Equation (4), the liquidus temperature of the slurry can increase by the enhancement in the squeeze pressure, which consequently increases the degree of subcooling of the slurry and prolongs the grain coarsening time. The slurry was forced to closely contact the surface of the mold by the increase in the squeeze pressure, which improved the heat transfer between the slurry and the mold, and therefore, the $\alpha$-Al grains did not have enough time to grow. The grains were forced to undergo a certain compression or elongation deformation to adapt to the filling movement of the slurry by the squeeze pressure, which caused a large number of grains compacted under the high pressure and therefore, the poor morphology and large size clusters were observed under the high squeeze pressure.

The mechanical properties of the scroll samples under different squeeze pressures after the T6 heat treatment are shown in Figure 10. The tensile strength increased from $341 \pm 7$ to $386 \pm 8 \mathrm{MPa}$ when the squeeze pressure increased from 25 to $100 \mathrm{MPa}$ but slightly decreased to $383 \pm 12 \mathrm{MPa}$ at the squeeze pressure of $125 \mathrm{MPa}$. Similarly, a significant growing trend was observed for the elongation (from $4.5 \pm 0.4 \%$ to $7.6 \pm 0.5 \%$ ) when the squeeze pressure was enlarged from 25 to $100 \mathrm{MPa}$. However, the elongation reduced to $7.5 \pm 0.9 \%$ at the squeeze pressure of $125 \mathrm{MPa}$. The yield strength increased from $214 \pm 5 \mathrm{MPa}$ at the squeeze pressure of $25 \mathrm{MPa}$ to $228 \pm 5 \mathrm{MPa}$ at the squeeze pressure of $100 \mathrm{MPa}$, which dramatically decreased to $212 \pm 5 \mathrm{MPa}$ when the semisolid billet was processed at the squeeze pressure of $125 \mathrm{MPa}$. This can be attributed to the change in the average grain size as the squeeze pressure rose. The hardness of the scroll sample increased from $98 \pm 6$ to $117 \pm 5 \mathrm{HV}$ when the squeeze pressure rose from 25 to $100 \mathrm{MPa}$, which remained almost stable under the squeeze pressure of $125 \mathrm{MPa}$. This was because the degree of compaction of the slurry continued to increase and gradually reached a stable value when the squeeze pressure increased. When it reached a certain value, a further increase in the squeeze pressure had no significant improvement in the degree of compaction, so its hardness did not continue to increase. Moreover, the adverse effect on the equipment would be obtained if the squeeze pressure is too high. Therefore, the squeeze pressure is recommended no more than $100 \mathrm{MPa}$ during the semisolid multicavity squeeze process. 

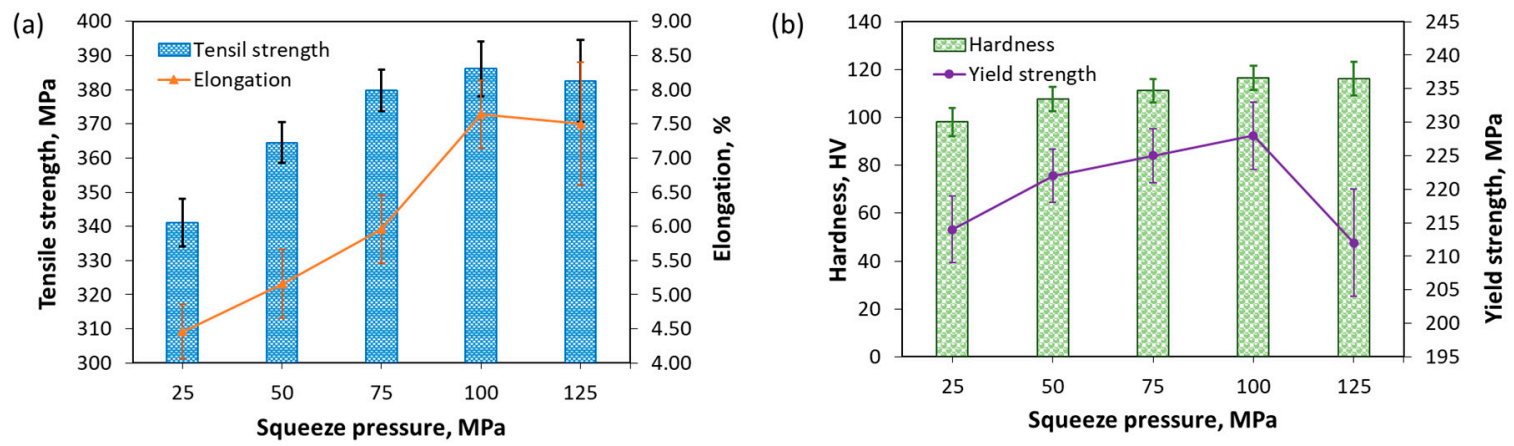

Figure 10. Effects of squeeze pressure on the mechanical property of scrolls: (a) tensile strength and elongation; (b) yield strength and hardness.

\subsection{Effects of Heat Treatment on the Microstructures and Mechanical Properties}

Based on the experimental results presented in Sections 3.1 and 3.2, the optimal operating range of the parameters was identified as $595-600{ }^{\circ} \mathrm{C}$ for the insulation temperature in Stage II and 75-100 MPa for the squeeze pressure in Stage III. Therefore, the microstructure of the scroll was processed at the insulation temperature of $600{ }^{\circ} \mathrm{C}$, and the squeeze pressure of $100 \mathrm{MPa}$ after the T6 heat treatment was obtained for analysis, as shown in Figure 11. It was found that the solute atoms in the 2A50 supersaturated solid solution were continuously enriched along the grain boundaries or other crystal planes to form segregation zones and gradually transformed into stable second-phase particles distributed around the grain boundaries through the T6 heat treatment. Therefore, the grain boundaries of the microstructure are more obvious compared to the microstructure of the scroll without the heat treatment, as shown in Figure 5c.

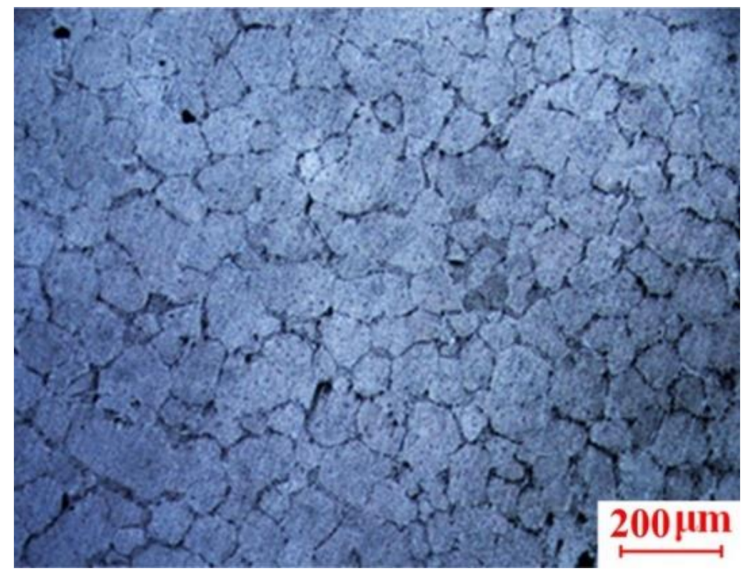

Figure 11. Microstructure of scrolls after the T6 heat treatment.

A comparison of the mechanical properties between the scrolls before and after the T6 heat treatment is shown in Table 3. It was found that the hardness, tensile strength, and yield strength of the scroll after the T6 heat treatment were higher than those without the T6 treatment. The hardness of the scroll increased from $73 \pm 4 \mathrm{HV}$ (before the T6 heat treatment) to $117 \pm 5 \mathrm{HV}$ (after the T6 treatment). The tensile strength was enhanced to $386 \pm 8 \mathrm{MPa}$, and the yield strength was increased to $228 \pm 5 \mathrm{MPa}$ through the T6 heat treatment. This was because a large number of strengthening phases were dispersed and precipitated evenly on the $\alpha$-Al grain boundary after the aging treatment of the supersaturated solid solution. These brittle and hard dispersion-strengthening phases were "pinned" on the grains or grain boundaries, which hindered the expansion of dislocation movement and increased the strength of the matrix [36]. Consequently, the tensile strength and the hardness were improved by the $\mathrm{T} 6$ heat treatment. 
However, the elongation of the scroll decreased after the T6 heat treatment, which reduced from $12.3 \pm 0.4 \%$ to $7.6 \pm 0.5 \%$. The partial dispersion-strengthening phase generated during the $\mathrm{T} 6$ heat treatment split the continuity of the microstructure. During the stretching process, although the $\alpha-\mathrm{Al}$ matrix has high plasticity and undergoes the macroscopic deformation with the sample, the hard and brittle particles, such as $\mathrm{CuAl}_{2}$, have extremely poor plasticity, which is prone to stress concentration. This stress concentration worked as the crack source, which caused the fracture of the strengthening phase on the matrix and the fusion of the microcrack. Therefore, the toughness and elongation decreased after the T6 treatment.

Table 3. Mechanical properties of scrolls before and after the T6 heat treatment.

\begin{tabular}{ccccc}
\hline Heat Treatment & $\begin{array}{c}\text { Hardness } \\
\text { (HV) }\end{array}$ & $\begin{array}{c}\text { Tensile Strength } \\
\mathbf{( M P a )}\end{array}$ & $\begin{array}{c}\text { Yield Strength } \\
\mathbf{( M P a )}\end{array}$ & $\begin{array}{c}\text { Elongation } \\
\mathbf{( \% )}\end{array}$ \\
\hline Before the T6 heat treatment & $73 \pm 4$ & $286 \pm 7$ & $124 \pm 6$ & $12.3 \pm 0.4$ \\
After the T6 heat treatment & $117 \pm 5$ & $386 \pm 8$ & $228 \pm 5$ & $7.6 \pm 0.5$ \\
\hline
\end{tabular}

\subsection{Macromorphology and Microstructures of the Scroll under the Optimal Process Parameters}

The macro morphology of the scroll obtained under the optimal process parameters (i.e., insulation temperature of $595^{\circ} \mathrm{C}$, squeeze pressure of $100 \mathrm{MPa}$ ) is shown in Figure 12. It was found that the scroll was fully filled, with clear outlines and smooth surfaces, without any obvious shrinkage, entrainment, cracks, mucosa, or any other common macro defects. The microstructure of different positions of the scroll labeled by A-F in Figure 12 is presented in Figure 13.
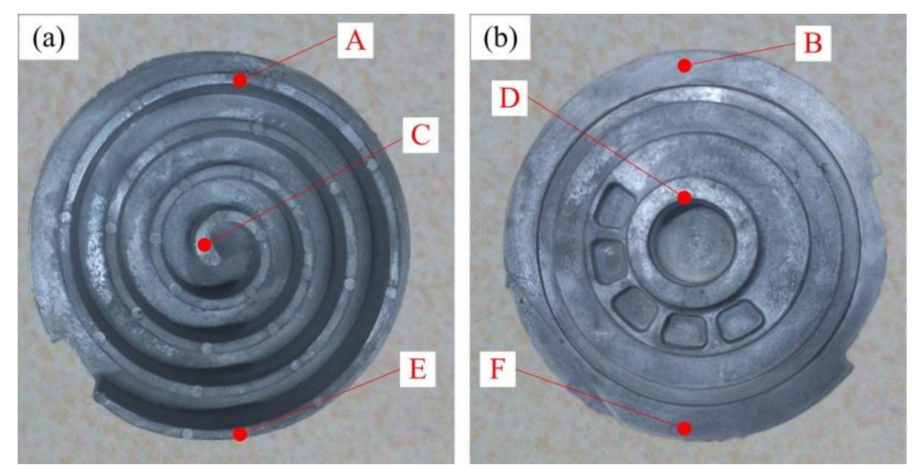

Figure 12. Macro morphology of the scroll: (a) front view and (b) back view.

It can be found in Figure 13 that the microstructure of the scroll was mainly composed of fine and spherical crystal grains. Although the grain distribution throughout the scroll was relatively uniform, a slight difference in the crystal grain morphology between different positions of the scroll was observed. As shown in Figure 13a,b, a large number of crystal grains were elongated or squashed at the location close to the inner gate (Positions A and B) during the flow filling process as they were directly affected by the squeeze pressure, which formed grain clusters with obvious directionality as the slurry flowed. Figure 13c,d illustrates that part of the crystal grains in the central region of the scroll (Positions $C$ and D) were elongated by contacting each other under the high-pressure condition. Some crystal grains even contacted and merged to form elongated crystal grains with irregular morphology. The obvious flow direction in the whole grain distribution can be observed in the microstructure of Positions $C$ and D. The grains were spherical at the bottom region of the scroll as it received less pressure due to the attenuation of the squeeze pressure along with the casting, which is shown in Figure 13e,f. Moreover, there was no obvious deformation observed at Positions E and F. 

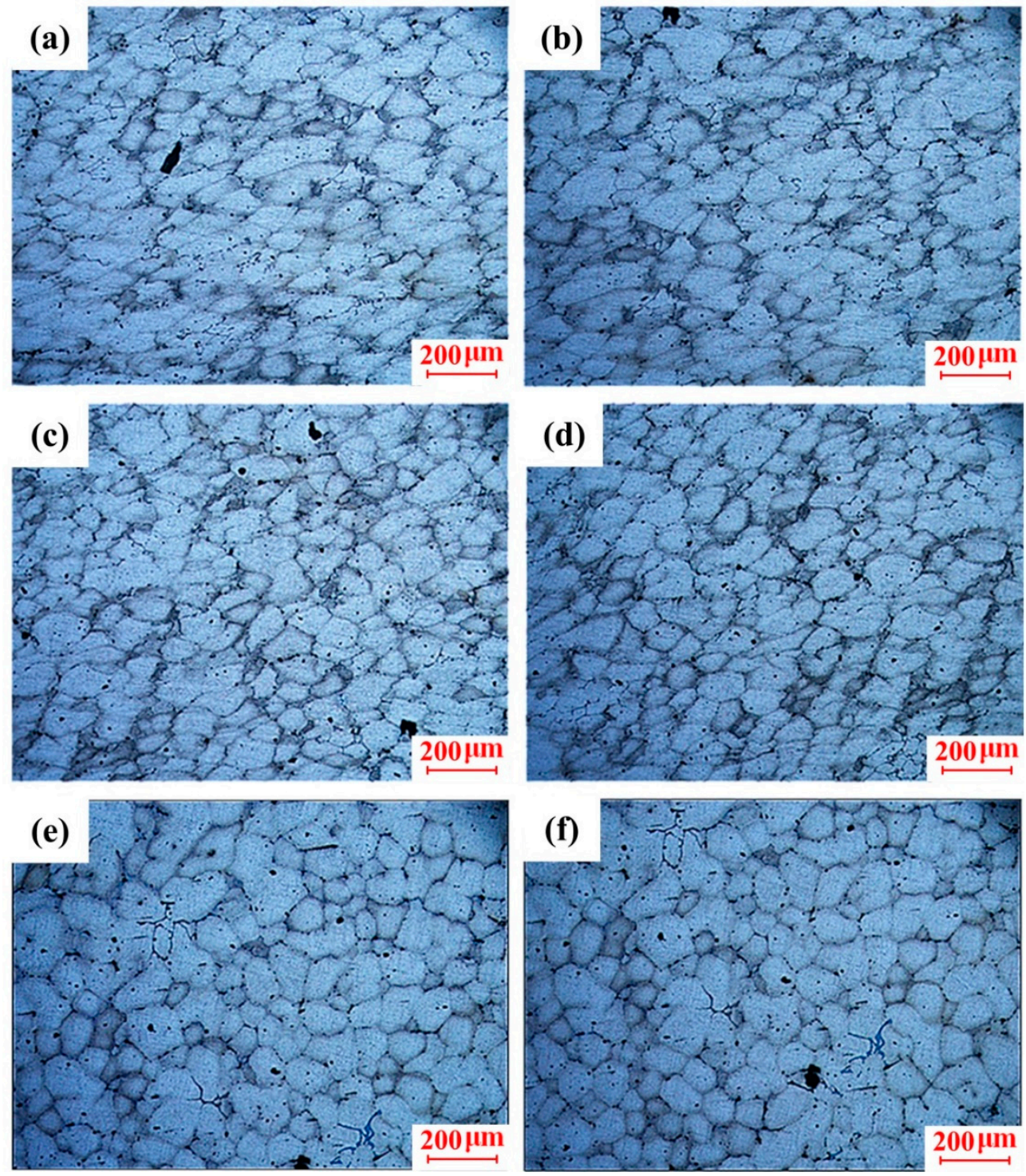

Figure 13. Microstructures at different positions of the scroll: (a) Position A in the top region, (b) Position B in the top region, (c) Position C in the central region, (d) Position D in the central region,

(e) Position E in the bottom region, and (f) Position F in the bottom region.

\section{Conclusions}

This paper proposes the EMS-based SMSC process for manufacturing aluminum alloy scrolls. The insulation temperature, squeeze pressure, and heat treatment of the micromorphology and the mechanical properties of the scroll are investigated experimentally. The main conclusions can be drawn as follows:

(1) The microstructures of the scroll at the liquid, near-liquid, and semisolid insulation temperature are composed of coarse dendrites, rose-like crystal grains, and near-spherical crystal grains, respectively. Reducing the insulation temperature can significantly reduce the grain size, improve the grain morphology, and enhance the mechanical properties.

(2) Reducing the insulation temperature to the semisolid range can decrease the grain size, increase the shape factor, and improve the mechanical properties. The minimum grain size was found as $111 \pm 3 \mu \mathrm{m}$ at the insulation temperature of $595^{\circ} \mathrm{C}$.

(3) Increasing the squeeze pressure is beneficial to reduce the microscopic pores of the microstructure, increase the compactness of the crystal grains, and improve the mechanical properties. However, 
the improvement in the mechanical properties is not obvious when the squeeze pressure exceeds $100 \mathrm{MPa}$. The maximum tensile strength, yield strength, and hardness were observed as $386 \pm 8 \mathrm{MPa}, 228 \pm 5 \mathrm{MPa}$, and $117 \pm 5 \mathrm{HV}$, respectively, at the squeeze pressure of $100 \mathrm{MPa}$.

(4) Although the tensile strength and hardness of the scroll can be improved by the T6 heat treatment, the elongation was reduced after the T6 heat treatment. The morphology of the grains is relatively round, and no obvious deformation was observed at the bottom part of the scroll casting due to the attenuation of the squeeze pressure.

(5) Based on the experimental results, the optimal process parameters are recommended as an insulation temperature of $595-600^{\circ} \mathrm{C}$ and a squeeze pressure of $100 \mathrm{MPa}$.

(6) Under the optimal process parameters, the scroll casting is completely filled, and there is no obvious shrinkage defect observed inside. Its microstructure is composed of fine and spherical grains. Some of the grains in the central region of the scroll are deformed by contact showing obvious flow direction. A large number of grains at the top region of the scroll casting are elongated or flattened and formed a cluster of crystal grains with strong orientation under the direct action of the squeeze pressure.

Author Contributions: Conceptualization, Y.W. and S.Z.; methodology, Y.W.; formal analysis, Y.G.; investigation, Y.G.; data curation, Y.W.; writing-original draft preparation, Y.G.; writing-review and editing, Y.W.; visualization, Y.G.; supervision, S.Z. All authors have read and agreed to the published version of the manuscript.

Funding: This research was funded by the Natural Science Basic Research Program of Shaanxi (Grant No. 2020JQ-067), the Open Foundation of the State Key Laboratory of Fluid Power and Mechatronic Systems (Grant No. GZKF-201912), and the State Key Laboratory of Materials Processing and Die and Mould Technology (Grant No. P2021-005).

Conflicts of Interest: The authors declare no conflict of interest.

\section{References}

1. Tello-Oquendo, F.M.; Navarro-Peris, E.; Barceló-Ruescas, F.; Gonzálvez-Maciá, J. Semi-empirical model of scroll compressors and its extension to describe vapor-injection compressors. Model description and experimental validation. Int. J. Refrig. 2019, 106, 308-326. [CrossRef]

2. Ma, X.; Zhang, C.; Li, K. Hybrid modeling and efficiency analysis of the scroll compressor used in micro compressed air energy storage system. Appl. Therm. Eng. 2019, 161, 114139. [CrossRef]

3. Zhang, Q.; Feng, J.; Wen, J.; Peng, X. 3D transient CFD modelling of a scroll-type hydrogen pump used in FCVs. Int. J. Hydrogen Energy 2018, 43, 19231-19241. [CrossRef]

4. Iglesias, A.; Favrat, D. Innovative isothermal oil-free co-rotating scroll compressor-expander for energy storage with first expander tests. Energy Convers. Manag. 2014, 85, 565-572. [CrossRef]

5. Wang, Y.-F.; Zhao, S.-D.; Guo, Y.; Yang, J.-L. Effects of process parameters on semi-solid squeeze casting performance of aluminum alloy scrolls for scroll compressors. China Foundry 2020, 17, 347-356. [CrossRef]

6. Jiang, Z.; Harrison, D.K.; Cheng, K. Computer-aided design and manufacturing of scroll compressors. J. Mater. Process. Technol. 2003, 138, 145-151. [CrossRef]

7. Yoshimura, H.; Tanaka, K. Precision forging of aluminum and steel. J. Mater. Process. Technol. 2000, 98, 196-204. [CrossRef]

8. Shan, D.B.; Xu, W.C.; Lu, Y. Study on precision forging technology for a complex-shaped light alloy forging. J. Mater. Process. Technol. 2004, 151, 289-293. [CrossRef]

9. Bayramoglu, M.; Polat, H.; Geren, N. Cost and performance evaluation of different surface treated dies for hot forging process. J. Mater. Process. Technol. 2008, 205, 394-403. [CrossRef]

10. Li, X.; Xiong, S.M.; Guo, Z. Correlation between Porosity and Fracture Mechanism in High Pressure Die Casting of AM60B Alloy. J. Mater. Sci. Technol. 2016, 32, 54-61. [CrossRef]

11. Zhang, P.; Li, Z.; Liu, B.; Ding, W.; Peng, L. Improved tensile properties of a new aluminum alloy for high pressure die casting. Mater. Sci. Eng. A 2016, 651, 376-390. [CrossRef]

12. Christy, J.V.; Arunachalam, R.; Mourad, A.-H.I.; Krishnan, P.K.; Piya, S.; Al-Maharbi, M. Processing, Properties, and Microstructure of Recycled Aluminum Alloy Composites Produced Through an Optimized Stir and Squeeze Casting Processes. J. Manuf. Process. 2020, 59, 287-301. [CrossRef] 
13. Shalaby, E.A.M.; Churyumov, A.Y.; Besisa, D.H.A.; Daoud, A.; Abou El-khair, M.T. A Comparative Study of Thermal Conductivity and Tribological Behavior of Squeeze Cast A359/AlN and A359/SiC Composites. J. Mater. Eng. Perform. 2017, 26, 3079-3089. [CrossRef]

14. Maj, J.; Basista, M.; Węglewski, W.; Bochenek, K.; Strojny-Nędza, A.; Naplocha, K.; Panzner, T.; Tatarková, M.; Fiori, F. Effect of microstructure on mechanical properties and residual stresses in interpenetrating aluminum-alumina composites fabricated by squeeze casting. Mater. Sci. Eng. A 2018, 715, 154-162. [CrossRef]

15. Ghomashchi, M.R.; Vikhrov, A. Squeeze casting: An overview. J. Mater. Process. Technol. 2000, 101, 1-9. [CrossRef]

16. Zhang, Y.; Wu, G.; Liu, W.; Zhang, L.; Pang, S.; Ding, W. Microstructure and mechanical properties of rheo-squeeze casting AZ91-Ca magnesium alloy prepared by gas bubbling process. Mater. Des. 2015, 67, 1-8. [CrossRef]

17. Wang, Y.; Zhao, S.; Zhao, X.; Zhao, Y. Microstructural coarsening of 6061 aluminum alloy semi-solid billets prepared via recrystallization and partial melting. J. Mech. Sci. Technol. 2017, 31, 3917-3923. [CrossRef]

18. Xu, Y.; Chen, C.; Jia, J.; Zhang, X.; Dai, H.; Yang, Y. Constitutive behavior of a SIMA processed magnesium alloy by employing repetitive upsetting-extrusion (RUE). J. Alloys Compd. 2018, 748, 694-705. [CrossRef]

19. Fu, J.L.; Jiang, H.J.; Wang, K.K. Influence of Processing Parameters on Microstructural Evolution and Tensile Properties for 7075 Al Alloy Prepared by an ECAPBased SIMA Process. Acta. Metall. Sin. 2018, 31, 337-350. [CrossRef]

20. Dao, V.; Zhao, S.; Lin, W.; Zhang, C. Effect of process parameters on microstructure and mechanical properties in AlSi9Mg connecting-rod fabricated by semi-solid squeeze casting. Mater. Sci. Eng. A 2012, 558, 95-102. [CrossRef]

21. Lü, S.; Wu, S.; Yang, X.; Hao, L.; Guo, W.; Fang, X. Microstructure and mechanical properties of Mg97Zn1Y2 alloy reinforced with LPSO structure produced by semisolid squeeze casting. Mater. Sci. Eng. A 2018, 732, 359-367. [CrossRef]

22. Wang, Y.; Zhao, S.; Zhang, C. Microstructures and mechanical properties of semi-solid squeeze casting ZL104 connecting rod. Trans. Nonferrous Met. Soc. 2018, 28, 235-243. [CrossRef]

23. Zhai, Y.; Liu, C.; Han, Z.; Wang, K. Semi-solid squeeze casting process of a ZL109 alloy. Rare Met. 2008, 27, 329-334. [CrossRef]

24. Masoumi, M.; Hu, H. Influence of applied pressure on microstructure and tensile properties of squeeze cast magnesium Mg-Al-Ca alloy. Mater. Sci. Eng. A 2011, 528, 3589-3593. [CrossRef]

25. Du, Y.; Lu, Y.; Wang, T.; Li, T.; Zhang, G. Effect of electromagnetic stirring on microstructure and properties of Al0.5CoCrCuFeNi alloy. Procedia Eng. 2012, 27, 1129-1134. [CrossRef]

26. Agrawal, S.; Ghose, A.K.; Chakrabarty, I. Effect of rotary electromagnetic stirring during solidification of In-situ Al-TiB2 composites. Mater. Des. 2017, 113, 195-206. [CrossRef]

27. Li, M.; Tamura, T.; Omura, N.; Murakami, Y.; Tada, S. Grain refinement of AZCa912 alloys solidified by an optimized electromagnetic stirring technique. J. Mater. Process. Technol. 2016, 235, 114-120. [CrossRef]

28. Chen, Y.; Zhang, L.; Liu, W.; Wu, G.; Ding, W. Preparation of Mg-Nd-Zn-(Zr) alloys semisolid slurry by electromagnetic stirring. Mater. Des. 2016, 95, 398-409. [CrossRef]

29. Ning, L.; Hong, Y.; Zhi-Wei, W. Effects of Heat Treatment on the Tribological Properties of Sicp/Al-5Si-1Cu-0.5Mg Composite Processed by Electromagnetic Stirring Method. Appl. Ences 2018, 8,372 .

30. Yu, H.Q.; Zhu, M.Y. Influence of electromagnetic stirring on transport phenomena in round billet continuous casting mould and macrostructure of high carbon steel billet. Ironmak. Steelmak. 2012, 39, 574-584. [CrossRef]

31. Wang, J.; Li, P.; Mi, G.; Zhong, Y. Microstructural evolution caused by electromagnetic stirring in superheated AlSi7Mg alloys. J. Mater. Process. Technol. 2010, 210, 1652-1659. [CrossRef]

32. Wang, Y.; Zhao, S.; Zhang, C. Grain Refinement of Aluminum Alloy Bar by a Modified RAP Process for Semi-Solid Forming. Mater. Trans. 2017, 58, 176-181. [CrossRef]

33. Schneider, M.; Werner, F.; Langenkämper, D.; Reinhart, C.; Laplanche, G. Effect of Temperature and Texture on Hall-Petch Strengthening by Grain and Annealing Twin Boundaries in the MnFeNi Medium-Entropy Alloy. Metals 2019, 9, 84. [CrossRef]

34. Hug, E.; Keller, C. Size effects and magnetoelastic couplings: A link between Hall-Petch behaviour and coercive field in soft ferromagnetic metals. Philos. Mag. 2019, 99, 1297-1326. [CrossRef] 
35. Venkatesan, S.; Xavior, M.A. Analysis of Mechanical Properties of Aluminum Alloy Metal Matrix Composite by Squeeze Casting_A Review. Mater. Today Proc. 2018, 5, 11175-11184. [CrossRef]

36. Vijian, P.; Arunachalam, V.P. Optimization of squeeze cast parameters of LM6 aluminium alloy for surface roughness using Taguchi method. J. Mater. Process. Technol. 2006, 180, 161-166. [CrossRef]

Publisher's Note: MDPI stays neutral with regard to jurisdictional claims in published maps and institutional affiliations.

(C) 2020 by the authors. Licensee MDPI, Basel, Switzerland. This article is an open access article distributed under the terms and conditions of the Creative Commons Attribution (CC BY) license (http://creativecommons.org/licenses/by/4.0/). 